\title{
Providing resistance to sulfide stress corrosion cracking of pipelines welded joints by selection of welding parameters
}

\author{
Artem Khudyakov ${ }^{1,2, *}$, Pavel Danilkin ${ }^{3,4}$ \\ ${ }^{1} R N$-BashNIPIneft Ltd, 450006 Ufa, Russia \\ ${ }^{2}$ Ural Federal University, 620002 Yekaterinburg, Russia \\ ${ }^{3}$ The Russian Research Institute of the Tube \& Pipe Industries, 454139, Chelyabinsk, Russia \\ ${ }^{4}$ South Ural State University, 454080, Chelyabinsk, Russia
}

\begin{abstract}
Sulfide stress cracking (SSC) is one of the most dangerous types of pipelines destruction. Thermal impact of the welding process drives to heterogeneity of the microstructure and properties of the metal, which can lead to cracking of pipeline welded joints. Resistance to SSC of welded joints is determined by the thermal cycle of welding and cooling rate in the temperature range of austenite transformation. Due to performed studies based on simulation of welding heating the recommended range of cooling rates of $10-30{ }^{\circ} \mathrm{C} / \mathrm{s}$ was established, in which the resistance to SSC of welded joints is ensured. To calculate the cooling rates in coarse grained heat affected zone (CGHAZ) finite-element models of heat distribution were developed for longitudinal multi-electrode submerged arc welding (SAW) and multi-pass girth welding of pipes. Using the developed welding models, it was found that in order to achieve the cooling rate in CGHAZ it is necessary to reduce heat input up to $15-30 \%$ during multi-electrode SAW process of longitudinal welds of pipes . For multi-pass girth welding it is necessary to preheat the edges to be welded up to $100-300{ }^{\circ} \mathrm{C}$ depending on type of welding (GMAW or SMAW) and pipe wall thickness.
\end{abstract}

\section{Introduction}

Large diameter pipes (LDP) are manufactured from microalloyed ferrite-bainite steels. For today, there is a wide experience of providing the required properties of the pipes' base metal for the oil and gas industry [1-3]. However, welded joints with pronounced structural, mechanical and electrochemical heterogeneity are the zone of predominant corrosion-mechanical destruction of pipes during transportation of hydrogen sulfidecontaining fluids and gases [4-7]. It is connected with the rapid heating and cooling during the welding process, a significant changes of the microstructure and the mechanical and corrosion properties of steel in CGHAZ of welded joints.

Despite the large amount of knowledge about the microstructure and properties formation in the base metal and welded joints of large diameter pipes, there is no data about the effect of the cooling rate in HAZ on the resistance of welded joints to SSC. This fact does not allow to purposefully control the technological welding process for the formation of favourable microstructure that ensures the resistance of welded joints to SSC. That is why, one of the important objectives of this study is to determine the range of cooling rates during welding, which ensures resistance of welded joints to SSC. Studies were carried out for API X65QS grade steel.

The purpose of this study was to determine the rational parameters of welding conditions for longitudinal and girth welded joints of pipes for ensuring the resistance of welded joints to SSC.

\section{Materials and Experimental Procedures}

To determine the sensitivity of steel to various types and modes of welding, expressed through heat input, the values of cooling rates in the temperature range of austenite decomposition of $800-500^{\circ} \mathrm{C}$ were used [8]

The study of API X65QS grade steel behavior in CGHAZ was carried out using welding heating and cooling simulation.

The chemical composition of the studied API X65QS steel is presented in table 1 .

Coupons were heated by induction to the temperatures of $1300-1350{ }^{\circ} \mathrm{C}$. After heating to a set temperature, specimens were cooling at rates of $0.1-300{ }^{\circ} \mathrm{C} / \mathrm{s}$ in the temperature range of $800-500{ }^{\circ} \mathrm{C}$.

To study the effect of the cooling rate after welding on the microstructure and characteristics of the metal in

\footnotetext{
* Corresponding author: Khudyakovao@bashneft.ru
} 
CGHAZ a complex analysis of coupons subjected to welding imitation was carried out:

- Analysis of the austenite phase transformations kinetics under conditions of various welding thermal cycles and the associated microstructure changes;

- metallographic studies;

- Hardness test by Vickers;

- CTOD test;

- SSC test according to NACE TM 0177, method A, Solution A.

Calculation of the cooling rates in CGHAZ was carried out using finite element models of welding heat distribution. Finite element models were developed for multi-electrode submerged arc welding (SAW) of longitudinal welded joints, for shielded metal arc welding (SMAW) and for gas metal arc welding (GMAW) of girth welded joints of pipes. The development of finite element models of welding and their numerical solution were carried out using the SYSWELD software package (License agreement No 2910-2014ДУ).

Table 1. The chemical composition of the studied API X65QS steel.

\begin{tabular}{|c|c|}
\hline Element & Mass fraction, $\%$ \\
\hline Carbon $(\mathrm{C})$ & 0,06 \\
\hline Silicon $(\mathrm{Si})$ & 0,35 \\
\hline Manganese (Mn) & 1,55 \\
\hline Sulfur (S) & 0,001 \\
\hline Phosphorus (P) & 0,006 \\
\hline Chromium (Cr) & 0,05 \\
\hline Nickel (Ni) & 0,23 \\
\hline Copper $(\mathrm{Cu})$ & 0,14 \\
\hline Molybdenum (Mo) & 0,004 \\
\hline Niobium $(\mathrm{Nb})$ & 0,048 \\
\hline Vanadium (V) & 0,03 \\
\hline Titanium (Ti) & 0,018 \\
\hline Calcium (Ca) & 0,002 \\
\hline Aluminum (Al) & 0,031 \\
\hline Nitrogen $(\mathrm{N})$ & 0,006 \\
\hline CEIIW & 0,35 \\
\hline CEPcm & 0,16 \\
\hline
\end{tabular}

\section{Experimental Results and Discussions}

\subsection{Effect of Cooling Rate on CGHAZ Properties}

Analysis of thermokinetic diagrams (Fig. 1) showed that the bainite transformation prevailed and was the main type of transformation. Bainite is present in the structure in a wide range of cooling rates, from $250{ }^{\circ} \mathrm{C} / \mathrm{s}$ to $1{ }^{\circ} \mathrm{C} / \mathrm{s}$. Pure bainite transformation takes place in the range of cooling rates of $10-120{ }^{\circ} \mathrm{C} / \mathrm{s}$ and has a transformation start temperature of $590-650{ }^{\circ} \mathrm{C} /$, the temperature of the transformation end is $450-540{ }^{\circ} \mathrm{C}$. This indicates a high structural stability of steel. Transformations with the formation of polygonal ferrite occur at cooling rates of less than $10^{\circ} \mathrm{C} / \mathrm{s}$.

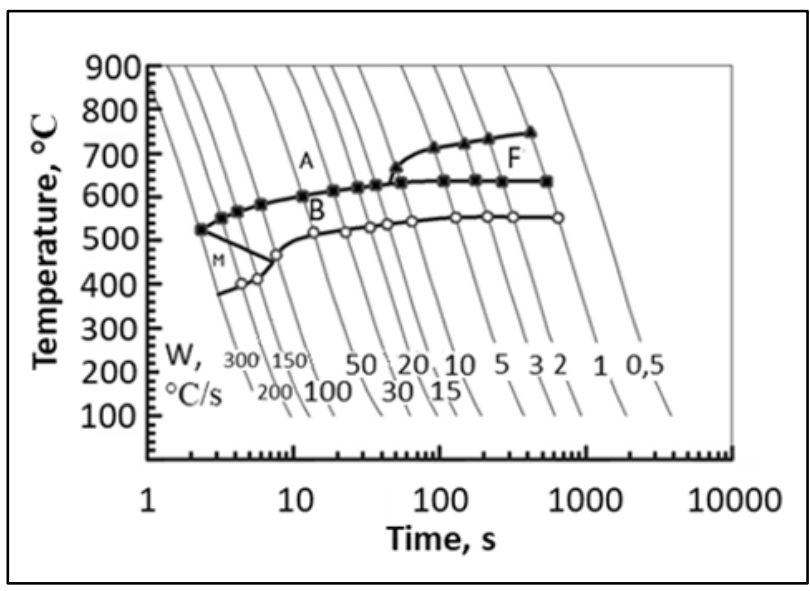

Fig.1. The kinetics of austenite transformation in the CGHAZ metal of the studied API X65QS steel.

Studying the hardness change in CGHAZ depending on the cooling rate (Fig. 2) and type of microstructure showed that in the area of ferrite-bainite and bainite transformations the hardness varies insignificantly from 205 to $220 \mathrm{HV}$ at cooling rates of $0.1-20{ }^{\circ} \mathrm{C} / \mathrm{s}$. A significant increase of hardness is observed in the area of bainitic transformation with a change of morphology from acicular to laths bainite at cooling speed higher than 20 ${ }^{\circ} \mathrm{C} / \mathrm{s}$.

According to the NACE MR0175 / ISO 15156-1, the suitability of steel pipes for transporting $\mathrm{H}_{2} \mathrm{~S}$-containing fluids is determined by the level of base metal and welded joints hardness. Hardness should not exceed 248_HV10. Steels with a hardness level exceeding this value is considered more susceptible to SSC. Thus, the requirements for hardness are achieved at cooling rates below $30^{\circ} \mathrm{C} / \mathrm{s}$. 


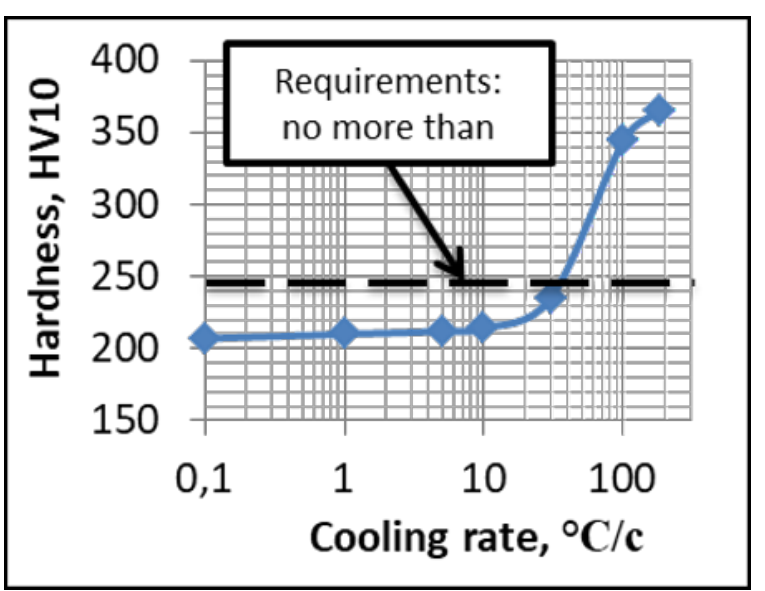

Fig. 2. The influence of the cooling rate on the hardness in CGHAZ of the studied API X65QS steel.

The SSC test results of coupons with simulated CGHAZ are presented in figure 3. Specimens with simulated CGHAZ corresponding to cooling rates in the range of 10 and $30{ }^{\circ} \mathrm{C} / \mathrm{s}$ passed the SSC test. The rest of the specimens did not withstand the basic test time of 720 hours and fractured.

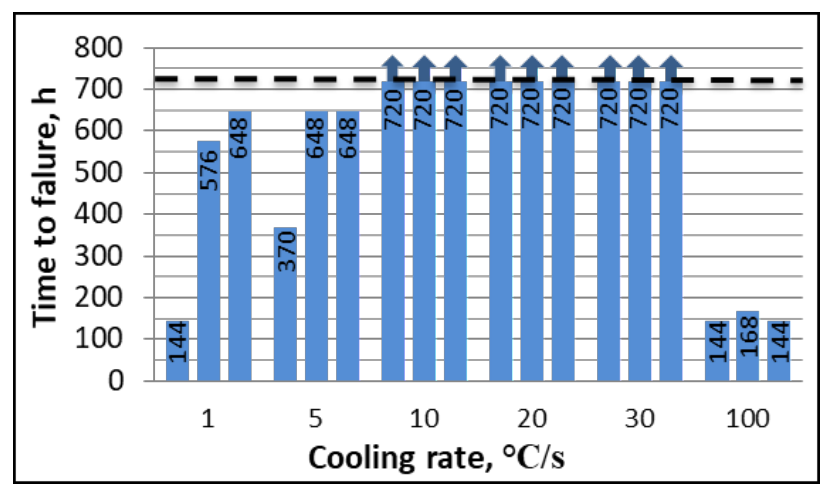

Fig. 3. SSC test results of specimens with simulated CGHAZ.

Comparison of data from structural studies and corrosion tests showed that the formation of acicular bainite (Fig. 4) provides resistance to SSC in CGHAZ of welded joints.

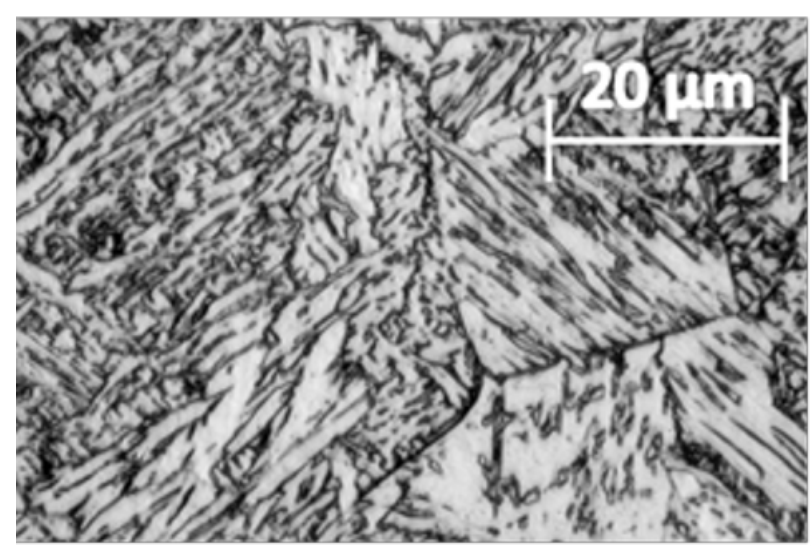

Fig. 4. The microstructure in CGHAZ formed in cooling range of $10-30^{\circ} \mathrm{C} / \mathrm{c}$.
Thus, to ensure requirements of hardness and resistance to SSC of welded joints, the cooling rate in $\mathrm{CGHAZ}$ should be in the range of $10-30^{\circ} \mathrm{C} / \mathrm{s}$.

\subsection{Finite Element Modelling of Welding}

\subsubsection{Submerged Arc Welding of Pipes}

LDP are manufactured by multiple-electrode SAW. During welding from 4 to 5 welding arcs act at the same time, that form one common welding pool. This process is characterized by high heat input, which leads to the rapid growth of grain in CGHAZ and a decrease of exploitation properties of welded joints. According to the theory of heat propagation in a solid [9] a flat layer scheme is adopted for the calculation of thermal cycles of LDP longitudinal welds. For modeling the distribution of volume heat generation density in a welding pool the double ellipsoid model proposed by J. A. Goldak [10] was adopted. Figure 5 shows adopted scheme of the temperature boundary problem.

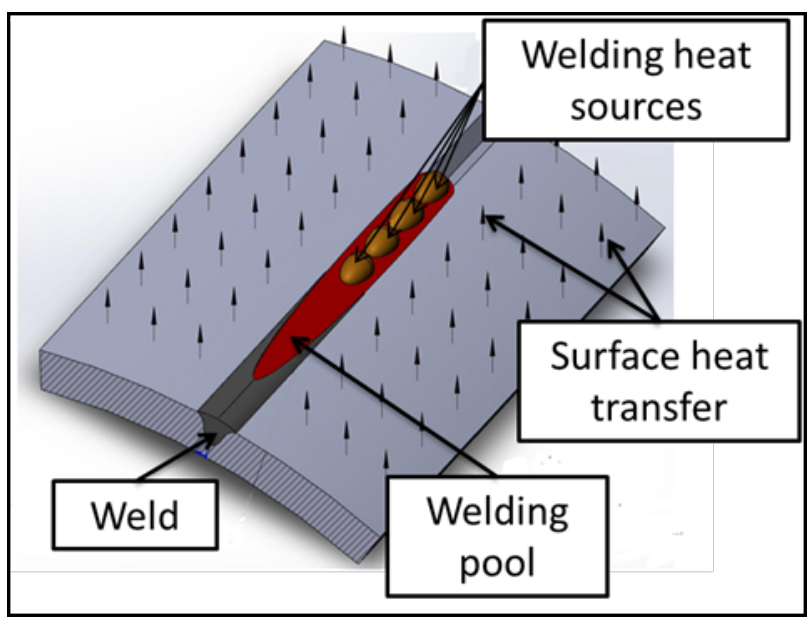

Fig 5. Temperature boundary problem for multiple-electrode SAW of LDP.

Common dependencies of the specific heat, thermal conductivity and total surface heat transfer [11, 12] on body temperature for low carbon steel were used for finite element model development. Figure 6 shows the numerical solution of the SAW finite element modelling. The developed finite element model with sufficient accuracy for practical purposes provides prediction of the geometric parameters of the weld and cooling rate in CGHAZ. The error of the calculated values relative to the practical results of longitudinal welding in the factory conditions does not exceed $10 \%$. The error arises due to the fact that the real conditions of welding are far from perfect, in contrast to the finite element model and the model does not take into account various deviations of the technological process and geometric parameters of the workpiece (offset of the edges, inconstancy of the gap and height of the technological weld, deviation of the values of the welding current, voltage and welding speed from the set ones and etc.)

As a result of the numerical solution of the heat distribution problem, the cooling rates in CGHAZ were 
determined for standard modes of pipe welding (Fig. 7). The CGHAZ cooling rates for pipes with wall thicknesses from 23 to $40 \mathrm{~mm}$ lie below the recommended range.

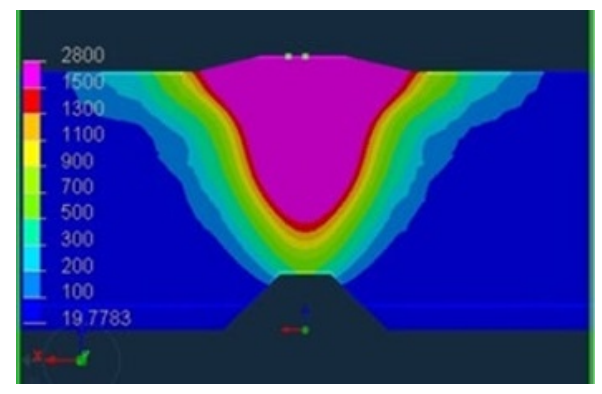

Fig. 6. Results of multiple-electrode SAW modelling for the $\varnothing 1153 \times 30,9 \mathrm{~mm}$ pipe, inner weld.

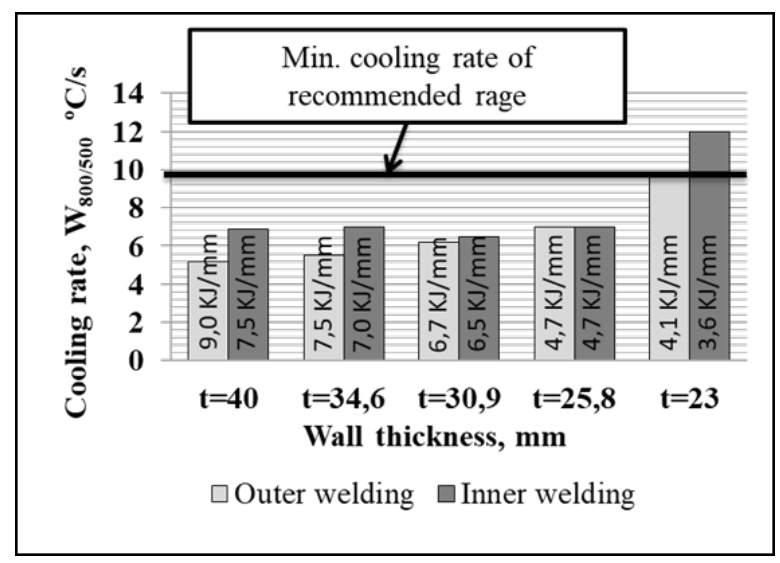

Fig. 7. The cooling rates in CGHAZ during welding of thickwalled LDP by standard modes.

\subsubsection{Girth Welding of Pipes}

Gas metal arc welding (GMAW) and shielded metal arc welding (SMAW) are used for girth welding during pipelines construction. Low heat input and high cooling rate characterize girth welding of pipes, which can lead to the formation of unfavorable martensitic structures and a decrease of welded joints corrosion properties. The root pass has the lowest heat input of welding and the highest cooling rate. That is why only the process of root pass welding is studied in this paper.

A flat layer scheme for heat propagation in a solid and model of the distribution of volume heat generation density in a welding pool by J. A. Goldak were adopted in finite element model of girth welding. To calculate the cooling rates at CGHAZ the most typical values of welding heat input were taken: $0,6 \mathrm{~kJ} / \mathrm{mm}$ for GMAW and $1,2 \mathrm{~kJ} / \mathrm{mm}$ for SMAW. Numerical solution of heat propagation problem for root pass welding of $20 \mathrm{~mm}$ wall thickness pipe is shown in figure 8 .

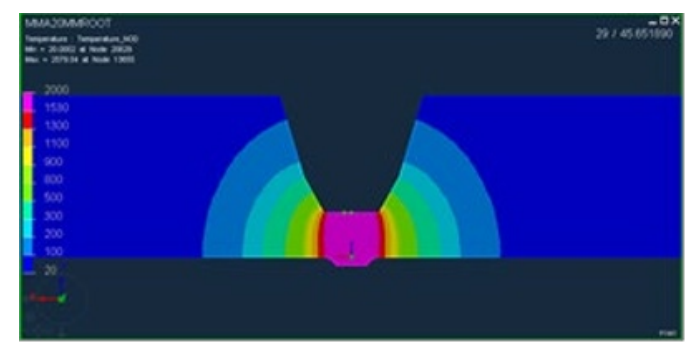

Fig. 8. Heat propagation during root pass welding of $20 \mathrm{~mm}$ wall thickness pipe.

\subsubsection{Results analysis}

Analysis of the obtained results showed that during GMAW and SMAW the cooling rate of the CGHAZ is significantly higher than the recommended range (Fig. 9)

The results of the finite element modeling show that for ensure of SSC resistance of longitudinal welded joints of pipes the cooling rate must be increased, but for girth welding, on the contrary, the cooling rate must be significantly reduced (Fig. 10). The increase of cooling rate during a longitudinal SAW can be achieved by reducing the total heat input of welding. But for girth welding of pipes a decrease of the cooling rate can be achieved by performing preheating of the edges.

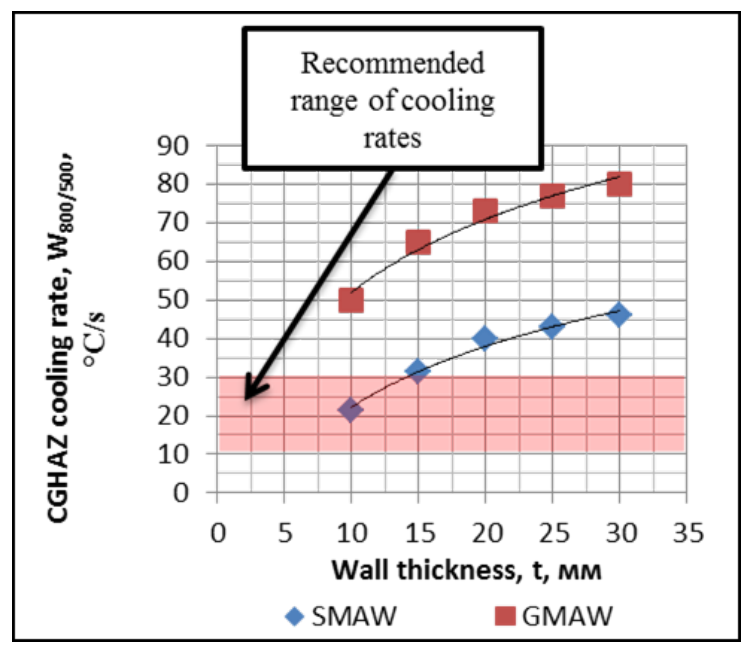

Fig. 9. The CGHAZ cooling rate dependence on wall thickness and type of welding.

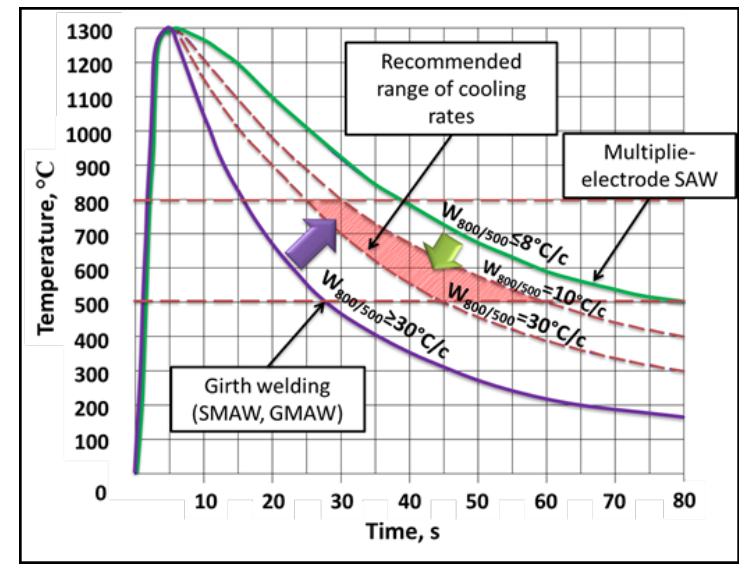

Fig. 10. Recommended range of cooling rate in CGHAZ. 


\subsection{Decisions}

\subsubsection{Heat Input Reduction for Submerged Arc Welding of Pipes}

According to the developed models it was found that it is necessary to reduce the total heat input of longitudinal welding up to $15-30 \%$, depending on the wall thickness of pipes. Reducing the diameter of welding arc leads to an increase of its pressure on the welding pool surface and an increase of its penetration depth. The increase of penetration depth of the first arc allows reducing the depth of edges bevelling and reducing the amount of deposited metal and significantly reducing the heat input. Finite element modelling of the proposed method for reducing heat input of multiple-electrode SAW of pipes with a wall thickness of 30,9 $\mathrm{mm}$ is shown in Figure 11. The proposed method allows to provide the required penetration depth and increase the cooling rate during submerged arc welding of pipes with, for example, $30,9 \mathrm{~mm}$ wall thickness up to $12-12.5^{\circ} \mathrm{C} / \mathrm{s}$ for the inner seam and up to $11-11.5^{\circ} \mathrm{C} / \mathrm{s}$ for the outer seam.

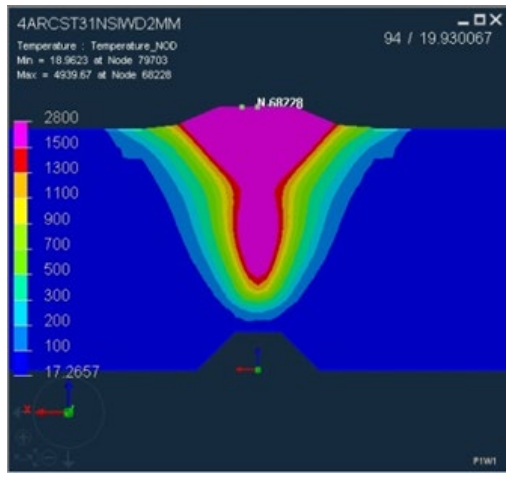

a)

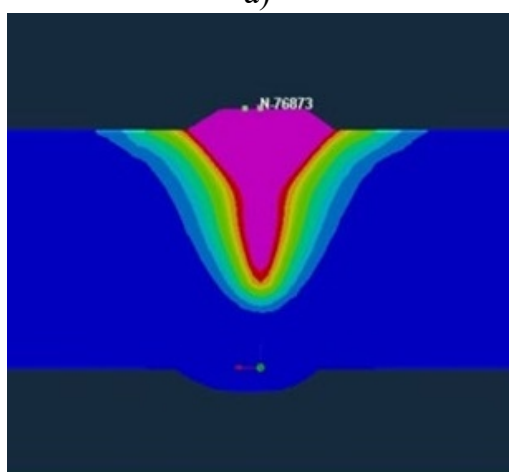

б)

Fig. 11. Modelling of submerged arc welding of pipe with 30,9 mm wall thickness with reduced heat input: a) inner welding; b) outer welding.

The proposed method of reducing the heat input for SAW was tested during manufacturing of an trial batch of $1153 \times 30,9 \mathrm{~mm}$ pipes. During experimental welding highquality welded joints without imperfections were obtained. The results of mechanical tests showed that welded joints completely satisfy the requirements of standards. Also, the welded joints showed high resistance to SSC.

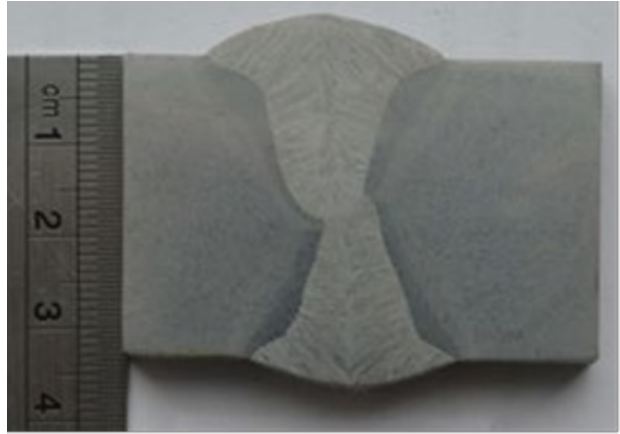

Fig. 12. Cross section of experimental longitudinal weld of $\varnothing 1153 \times 30,9 \mathrm{~mm}$ pipe.

\subsubsection{Preheating of Edges for Girth Welding of Pipes}

The developed finite element models of pipe girth welding allowed analysing the effect of preheating temperature of the edges on the cooling rate during welding of a root pass. Figure 13 shows the influence of preheating temperature on cooling rate in CGHAZ of root pass. Analysis of the results showed that preheating temperature of the edges should be $100-200{ }^{\circ} \mathrm{C}$ depending on the wall thickness for SMAW and $200-300{ }^{\circ} \mathrm{C}$ for GMAW.

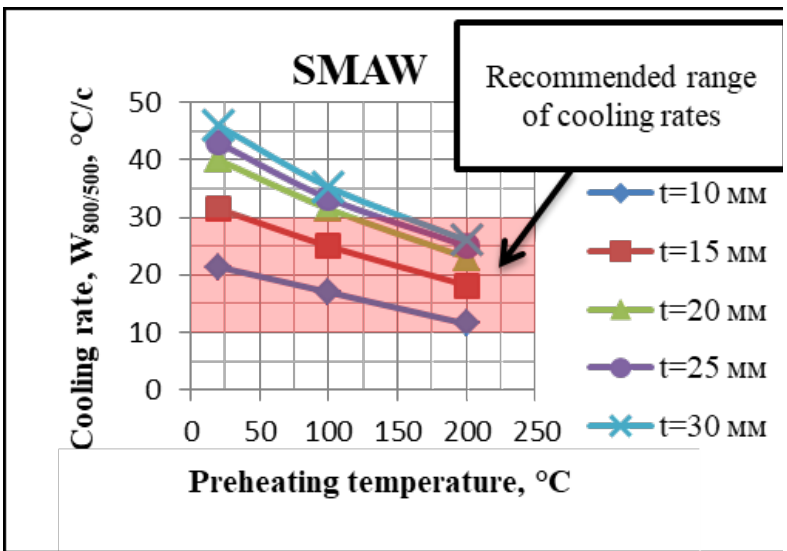

a)

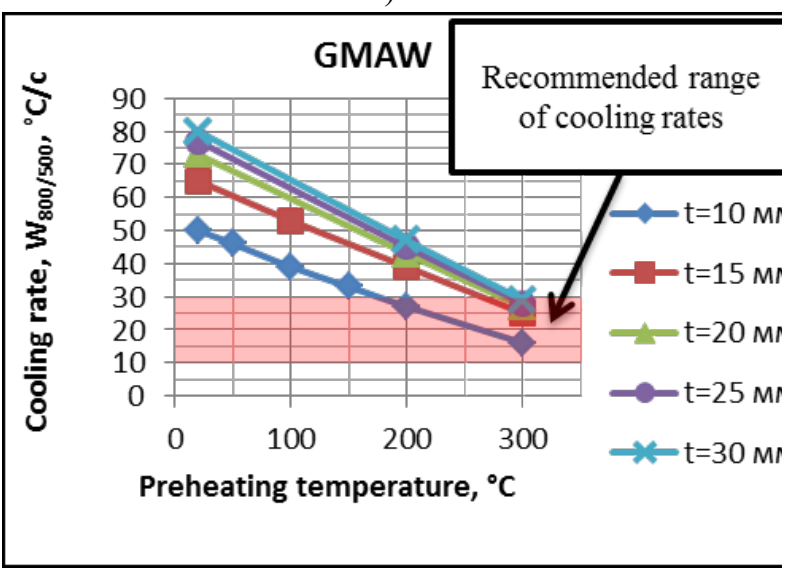

b)

Fig. 13. The influence of preheating temperature and wall thickness $(t)$ on cooling rate in CGHAZ of root pass: a) SMAW; b) GMAW. 


\section{Conclusions}

1. The performed studies allowed to establish the recommended range of cooling rates in CGHAZ during welding of pipes designed for the transportation of $\mathrm{H}_{2} \mathrm{~S}$ containing fluids and gases. To ensure the resistance of welded joints to SSC, it is necessary to provide the cooling rate at the CGHAZ in the range of $10-30{ }^{\circ} \mathrm{C} / \mathrm{s}$.

2.It is necessary to reduce the total heat input of longitudinal welding up to $15-30 \%$, depending on the wall thickness of pipes. The method of reducing heat input energy of multi-electrode SAW was proposed and tested during manufacturing of experimental lot of $\varnothing 1153 \times 30,9$ pipes. The proposed method allowed to increase the cooling rate in CGHAZ up to $11-12^{\circ} \mathrm{C} / \mathrm{s}$ and to ensure $\mathrm{SSC}$ resistance of longitudinal welded joints of pipes.

3. The cooling rate in CGHAZ of girth welded joints of pipes in the recommended range and their SSC resistance can be provided by preheating of the edges. The preheating temperature of the edges should be 100-200 ${ }^{\circ} \mathrm{C}$ depending on the wall thickness for SMAW and 200$300{ }^{\circ} \mathrm{C}$ for GMAW.

\section{References}

1. A. Kaletin, Yu. Kaletina, Bul. PNRPU. Mech. Eng., mat. sci.. Vol. 16, No. 4, pp. 22-30 (2014)

2. A. Maltseva, "Investigation of the structures and properties of high-strength ferritic-bainitic steels intended for high-pressure pipelines". Phd diss. Chelybinsk, Russia. 194 p. (2012).

3. A. Holodnyj, Resistance improvement against hydrogen cracking of pipe steels sheets based on the control of structure formation in the central segregation zone during thermomechanical processing. Phd diss. Moscow, Russia. 187 p. (2016).

4. C. Nekrasova, T. Olshanskaya, Bul. PNRPU. Mech. Eng., mat. sci. Vol. 16, No3, pp. 21-29 (2014).

5. L. Vyboyschik, R. Luchkin, S. Platonov, Svar. Proizv. No. 6. pp. 12-16 (2008)

6. V. Zagoryanskij, Bul. KrNU. No.2 prt. 1. pp. 61-68. (2010)

7. D. Varlamov, I. Barenboym, O. Steklov, Oil \& gas terr., No. 6, pp. 36-44 (2012)

8. Rosentahl D. Transact. ASME N.11, pp.849-865. (1946)

9. I. Rykalin, Calculations of thermal processes during welding. Moscow. 296 p. (1951)

10. J. Goldak, M. Akhlaghi, Computation welding mechanics. Springer Science + Business Media Inc., Boston, (2005).

11. A. Konovalov, A. Kurkin, E. Makarov, V. Nerovnij, B. Yakushin, Theory of welding processes. Moscow. 752 p. (2007)

12. K. Bagryanskij, Z. Dobrotina, K. Hrenov, Theory of welding processes. Kiev. 424 p. (1976) 